\title{
Lasia spinosa Chemical Composition and Therapeutic Potential: A Literature-Based Review
}

\author{
Rajib Hossain, ${ }^{1}$ Cristina Quispe, ${ }^{2}$ Jesús Herrera-Bravo ${ }^{10,4}$ Md. Shahazul Islam, ${ }^{1}$ \\ Chandan Sarkar, ${ }^{1}$ Muhammad Torequl Islam, ${ }^{1}$ Miquel Martorell $@{ }^{5,6}$ \\ Natália Cruz-Martins $\odot,{ }^{7,8,9,10}$ Ahmed Al-Harrasi, ${ }^{11}$ Ahmed Al-Rawahi, ${ }^{11}$ \\ Javad Sharifi-Rad $\odot{ }^{12}$ Manshuk Ibrayeva, ${ }^{13}$ Sevgi Durna Daştan, ${ }^{14,15}$ \\ Mohammed M. Alshehri $\mathbb{C}^{16},{ }^{16}$ Daniela Calina $\mathbb{D}^{17},{ }^{17}$ and William C. Cho $\mathbb{1}^{18}$ \\ ${ }^{1}$ Department of Pharmacy, Life Science Faculty, Bangabandhu Sheikh Mujibur Rahman Science and Technology University, \\ Gopalganj 8100, Bangladesh \\ ${ }^{2}$ Facultad de Ciencias de la Salud, Universidad Arturo Prat, Avda. Arturo Prat 2120, Iquique 1110939, Chile \\ ${ }^{3}$ Departamento de Ciencias Básicas, Facultad de Ciencias, Universidad Santo Tomas, Chile \\ ${ }^{4}$ Center of Molecular Biology and Pharmacogenetics, Scientific and Technological Bioresource Nucleus, Universidad de La Frontera, \\ Temuco 4811230, Chile \\ ${ }^{5}$ Department of Nutrition and Dietetics, Faculty of Pharmacy, And Centre for Healthy Living, University of Concepción, \\ 4070386 Concepción, Chile \\ ${ }^{6}$ Universidad de Concepción, Unidad de Desarrollo Tecnológico, UDT, Concepción 4070386, Chile \\ ${ }^{7}$ Department of Biomedicine, Faculty of Medicine, University of Porto, Alameda Prof. Hernâni Monteiro, Porto, Portugal \\ ${ }^{8}$ Institute for Research and Innovation in Health (i3S), University of Porto, Porto, Portugal \\ ${ }^{9}$ Institute of Research and Advanced Training in Health Sciences and Technologies (CESPU), Rua Central de Gandra, 1317, \\ 4585-116 Gandra PRD, Portugal \\ ${ }^{10}$ TOXRUN - Toxicology Research Unit, University Institute of Health Sciences, CESPU, CRL, 4585-116 Gandra, Portugal \\ ${ }^{11}$ Natural and Medical Sciences Research Centre, University of Nizwa, Birkat Almouz, 616, Oman \\ ${ }^{12}$ Facultad de Medicina, Universidad del Azuay, Cuenca, Ecuador \\ ${ }^{13}$ Faculty of Science and Technology, The Caspian University of Technology and Engineering Named after Sh. Yessenov, \\ Aktau, Kazakhstan \\ ${ }^{14}$ Department of Biology, Faculty of Science, Sivas Cumhuriyet University, 58140 Sivas, Turkey \\ ${ }^{15}$ Beekeeping Development Application and Research Center, Sivas Cumhuriyet University, 58140 Sivas, Turkey \\ ${ }^{16}$ Pharmaceutical Care Department, Ministry of National Guard-Health Affairs, Riyadh, Saudi Arabia \\ ${ }^{17}$ Department of Clinical Pharmacy, University of Medicine and Pharmacy of Craiova, 200349 Craiova, Romania \\ ${ }^{18}$ Department of Clinical Oncology, Queen Elizabeth Hospital, Kowloon, Hong Kong
}

Correspondence should be addressed to Natália Cruz-Martins; ncmartins@med.up.pt,

Javad Sharifi-Rad; javad.sharifirad@gmail.com, Daniela Calina; calinadaniela@gmail.com, and William C. Cho; chocs@ha.org.hk

Received 5 May 2021; Revised 8 November 2021; Accepted 3 December 2021; Published 28 December 2021

Academic Editor: German Gil

Copyright (C) 2021 Rajib Hossain et al. This is an open access article distributed under the Creative Commons Attribution License, which permits unrestricted use, distribution, and reproduction in any medium, provided the original work is properly cited.

Lasia spinosa (L.) is used ethnobotanically for the treatment of various diseases, including rheumatoid arthritis, inflammation of the lungs, bleeding cough, hemorrhoids, intestinal diseases, stomach pain, and uterine cancer. This review is aimed at summarizing phytochemistry and pharmacological data with their molecular mechanisms of action. A search was performed in databases such as PubMed, Science Direct, and Google Scholar using the keywords: "Lasia spinosa," then combined with "ethnopharmacological use," "phytochemistry," and "pharmacological activity." This updated review included studies with in vitro, ex vivo, and in vivo experiments with compounds of known concentration and highlighted pharmacological 
mechanisms. The research results showed that L. spinosa contains many important nutritional and phytochemical components such as alkanes, aldehydes, alkaloids, carotenoids, flavonoids, fatty acids, ketones, lignans, phenolics, terpenoids, steroids, and volatile oil with excellent bioactivity. The importance of this review lies in the fact that scientific pharmacological evidence supports the fact that the plant has antioxidant, anti-inflammatory, antimicrobial, cytotoxic, antidiarrheal, antihelminthic, antidiabetic, antihyperlipidemic, and antinociceptive effects, while protecting the gastrointestinal system and reproductive. Regarding future toxicological and safety data, more research is needed, including studies on human subjects. In light of these data, L. spinosa can be considered a medicinal plant with effective bioactives for the adjuvant treatment of various diseases in humans.

\section{Introduction}

Traditional, herbal, and Ayurvedic medicine comprise an important and prestigious form of treatment for various diseases and conditions in different locations all over the world from the beginning of human civilization on Earth [1]. Several plants and their corresponding preparations have been used for various therapeutic purposes for a long time ago. The history of traditional, herbal, and Ayurvedic medicine is the eldest to establish a treatment pattern [1].

Lasia spinosa (L.) Thwaites, often known as Chengmora/ Sibru in Assames, Kata-kachu in Bengali, Janum-Saru in Manipuri, Kohila/Mahakohila/Engilikohila in Sri Lanka, Zawangzang in Mizoram, and Laksmana in Sanskrit [2-4], belongs to the Araceae family [5]. It is found in Asia-Bangladesh, China, the Indian subcontinent, Myanmar, Thailand, Indo-China, Indonesia, and Papua New Guinea [6].

Briefly, L. spinosa is an aquatic or terrestrial plant, shortstemmed spiny heirs with underground rhizome that usually occurs in wet forests, open marshes, wetlands, or in permanently standing water [7]. L. spinosa is a large marsh plant with the stem stout $1 \mathrm{~m}$ high and the leaves broadly arrowshaped in outlines, $20-30 \mathrm{~cm}$ long deeply divided into 4-6 pairs of narrow side lobes. The petiole is $30-40 \mathrm{~cm}$ long, veins beneath the petiole and peduncle prickly [8]. Morpho-anatomical feature of $L$. spinosa has been recently reported by Lakshmi et al. [9]. The plant is harvested from the wild for its edible leaves and various medicinal uses. Sometimes, it is also cultivated as a vegetable crop along ponds margins [10]. Recently, it has been reported that Fusarium fujikuroi caused leaf spot on $L$. spinosa in China [11].

With regards to their biological effects, the tender leaves and rhizomes of this plant, used as a vegetable and in indigenous medicine, have been recommended for a variety of conditions [12-15].

Given the multiple potentialities of this plant, this review provides up-to-date data on $L$. spinosa chemical composition and biological effects based on the scientific reports found in the databases.

\section{Review Methodology}

In this study, the literature on botanical classification of $L$. spinosa, ethnomedicinal applications, secondary metabolites, biological properties were compiled, reviewed, and summarized. For the compilation of all written papers on this species, scientific search engines such as PubMed, ScienceDirect, SpringerLink, Web of Science, Scopus, Wiley
Online, Scifnder, and Google Scholar have been used. In this study, the literature on botanical classification of Lasia spinosa, ethnomedicinal applications, secondary metabolites, and biological properties were compiled, reviewed, and summarized. For searching, the next MeSH terms were used: "Phytotherapy", "Plants", "Medicinal", "Plant Extracts/ administration \& dosage", "Plant Extracts/isolation \& purification", "Plant/chemistry", "Structure-Activity Relationship", "Disease Models", "Animal", and "Plant Extracts/ toxicity". Using the Chemsketch version 12.01 program, chemical structures were drawn. The scientific names of the plants have been verified according to the PlantList $[16,17]$.

Inclusion criteria: works published in English on Lasia spinosa that highlighted the following data: chemical compounds isolated from each genus, preclinical pharmacological research highlighting molecular mechanisms, and in vitro/in vivo pharmacological studies that contained the concentration and dose at which the chemical compounds studied were pharmacologically active and toxicological data. The most important results obtained were summarized in the tables.

Exclusion criteria: abstracts, letters to the editor, papers in languages other than English, studies that did not have dose-effect correlations, and studies that did not have proven molecular mechanisms which underline the pharmacology.

\section{Ethnopharmacology}

L. spinosa is a medicinally important plant, traditionally used by different ethnic communities all over the world. There are various reports on L. spinosa medicinal and economical properties. Often used for treating colic, tuberculosis of lymph nodes, swollen lymph nodes, rheumatism/ rheumatoid arthritis, injuries, snake bites, and insect bites, this plant is also recommended as effective for the treatment of sore throat, constipation, to purify the blood, on lung inflammation, bleeding cough, and uterine cancer [14, 18-20]. Rhizomes (roots) are most often used as a remedy for hemorrhoids in Sri Lanka and Malays and to confer protection for some of the above conditions, because of their high fibre content and antioxidant compounds [15].

Besides, leaves and stalks have demonstrated profound antihelminthic, anticestode, and antinematode efficacy [12, $15,18,19,21,22]$. The root decoction is also useful in gastrointestinal diseases and stomachache [4], while also stimulating liver function [22]. Paste from tender leaves is externally used in burns [4]. 


\section{Phytochemical Profile}

L. spinosa whole plant contains several essential phytochemicals, including alkaloids, flavonoids, tannin, saponins, steroids, terpenoids, and varying amounts of micronutrients, like zinc $(\mathrm{Zn})$, magnesium $(\mathrm{Mg})$, calcium $(\mathrm{Ca})$, iron $(\mathrm{Fe})$, copper $(\mathrm{Cu})$, manganese $(\mathrm{Mn})$, and molybdenum (Mo) (Table 1).

Nutritional analysis of $L$. spinosa showed that it contains proteins $(17.6 \mathrm{kcal} / 100 \mathrm{~g})$, fats $(1.16 \mathrm{kcal} / 100 \mathrm{~g})$, and carbohydrates $(35.7 \mathrm{kcal} / 100 \mathrm{~g})$, with a nutritive value of $224 \mathrm{kcal} / 100 \mathrm{~g}[2,23]$. In another study, the protein, fats, and carbohydrate content on a dry weight basis were 17.9, 3.8 , and $45.5 \mathrm{~g} / 100 \mathrm{~g}$ edible portion for protein, fats, and carbohydrate, respectively, for $L$. spinosa leaf, with a nutritive value of $288.5 \mathrm{kcal} / 100 \mathrm{~g}$ [24]. L. spinosa roots/rhizome contains dietary fibre, $\mathrm{Ca}$, and provitamin A carotenoids [18, 25]. L. spinosa leaf contains $15.4 \mathrm{~g}$ of fibre, $250 \mathrm{mg}$ of $\mathrm{Ca}$, $19.2 \mathrm{mg}$ of $\mathrm{Fe}$, and $455 \mathrm{mg}$ of vitamin C for $100 \mathrm{~g}$ edible portion on a dry weight basis $[24,26]$.

In fresh weight, other studies reported content of proteins, fats, and carbohydrates of $3.68 \pm 0.28,0.44 \pm 0.03$, and $4.78 \pm 0.38 \mathrm{~g} / 100 \mathrm{~g}$, respectively, the mineral content of $158.08 \pm 3.98,321.73 \pm 7.00,73.17 \pm 2.37,53.86 \pm 3.86$, and $0.92 \pm 0.08 \mathrm{mg} / 100 \mathrm{~g}$ for $\mathrm{Ca}, \mathrm{K}, \mathrm{P}, \mathrm{Mg}$, and $\mathrm{Fe}$, and $2.99 \pm$ 0.11 and $0.28 \pm 0.01 \mathrm{mg} / 100 \mathrm{~g}$ of vitamins $\mathrm{C}$ and $\mathrm{E}$, respectively [27].

When specifically addressing the different extracts prepared from L. spinosa, hexane extracts leaves and root contains the alkaloid berberine [28], lignan (e.g., lyoniresinol, meridional, secoisolariciresinol; 5, $5^{\prime}$-dimethoxysecoiso-lariciresinol; 2-(4-hydroxy-3,5-dimethoxybenzyl)-3-(4hydroxy-3-methoxybenzyl)-1,2-butanediol; ( $\left.7^{\prime} \mathrm{S}, 8 \mathrm{~S}, 8 \mathrm{R}\right)-4,4^{\prime}$ -dihydroxy-3,3' 5,5' -tetra methoxy-7',9-eproxylignan- $9^{\prime}$-ol7-one; 5,5'-dimethoxy-lariciresinol; $5^{\prime}$-methyoxlariciresinol, dihydrodehydrodiconifery alcohol; syringaresinol) [27-29], aldehyde (e.g., p-hydroxy benzaldehyde) [30], phenolic (e.g., procyanidin A1) [31] and other compounds (e.g., 4-hydroxybenzoic acid, 2-(4'- methoxyphenyl)-ethanol, 4methoxyphenyl alcohol, 1-tetracosane) [30], from stem carotenoids (e.g., $\alpha$-carotene, $\beta$-carotene, $\beta$-carotene-5,6, $5^{\prime}$ , $6^{\prime}$-diepoxide; $5,6,5^{\prime}, 6^{\prime}$-diepoxy-5, 8, 5', $8^{\prime}$-tetrahydro- $\beta$, cis-neoxanthin, and unidentified carotenoids I, II, III, and IV) are isolated [24, 32, 33].

The aerial parts of $L$. spinosa contain terpenoids (e.g., limonene, aqualene, caryophyllene), volatile oil (e.g., methyl octadec-6,9-dien-12-ynoate, $\alpha$-glyceryl-linolenate $\alpha$-pinene, $\alpha$-selinene, camphene, $\delta$-3-carene, camphor) [21, 34], phenolic compounds (e.g., 4-hydroxybenzoic acid, morin, cinnamic acid, syringic acid, gentisic aid) [21, 28, 34], fatty acids (e.g., methyl ester of oleic acid, palmitic acid, stearic acid, epoxyoleic acid) [34], steroids (e.g., spinasterone, $\beta$ sitosterol, $\gamma$-sitosterol, stigmasterol, campesterol, crinosterol) [21, 34], alkane (e.g., hexatriacontane and heptacosane) [35].

The whole plant contains phenolics (e.g., gentisic acid, isovanilic acid, syringic acid, chlorogenic acid, p-hydroxy benzoic acid, (+)-catechin) [28], flavonoids including flavonoid glycosides and flavonoid aglycones (e.g., vitexin,
TABLE 1: Amounts of micronutrients of Lasia spinosa in ppm (parts per million) [2].

\begin{tabular}{lc}
\hline Elements & Amounts (ppm) \\
\hline $\mathrm{Zn}$ & $7.442 \pm 0.01$ \\
$\mathrm{Mg}$ & $6.228 \pm 0.11$ \\
$\mathrm{Fe}$ & $17.06 \pm 0.87$ \\
$\mathrm{Cu}$ & $0.316 \pm 0.02$ \\
$\mathrm{Mn}$ & $1.334 \pm 0.08$ \\
$\mathrm{Mo}$ & $1.180 \pm 0.06$ \\
\hline
\end{tabular}

vitexin-2"-O- $\beta$-D-glucopyranoside; isorhamnetin 3-O-rutinoside, morin, apigenin, $3^{\prime}$-methyl-quercetin-3-O- $\alpha$-Lrhamnopyranosyl-(1/6) $\beta$-D-glucopyranoside; triglochinin) $[28,32,35]$, and ketone (e.g., hexahydrofarnesyl acetone) (21).

The chemical structures of such compounds are shown in Table 2 and Figure 1.

\section{Pharmacological Properties: Mechanisms and Targeted Molecular Pathways}

5.1. Antioxidant. Oxidative stress is the basis of premature ageing of the body, the basis of disease, and is triggered by free radicals [29] more precisely occurs as a result of the imbalance between the amount of reactive oxygen produced in the body and its ability to eliminate it $[30,31]$. Oxidative stress can be alleviated by approaching a balanced lifestyle that includes a healthy diet and sports [32]. Physical exercise reduces cellular oxidation by deep oxygenating tissues, eliminating stress, and relaxing the body [33]. On the other hand, the diet has a very important role, and the best treatment against oxidative stress is antioxidants [34]. They are found in many herbs and can kill free radicals [35, 37]. Medicinal plants usually contain a high level of antioxidants that can counteract the oxidative stress process linked to a disease $[38,39]$.

The free radical scavenging activity of $L$. spinosa leaves extracts on 1,1-diphenyl-2-picrylhydrazyl (DPPH) had been assessed and showed significant antioxidant activities [40]. The ethyl acetate fraction showed the highest free radical scavenging activity $\left(\mathrm{IC}_{50}=16.42 \mu \mathrm{g} / \mathrm{mL}\right)$ when compared to the positive control-butylated hydroxytoluene (BHT). At the same time, the aqueous fraction also exhibited moderate antioxidant potential $\left(\mathrm{IC}_{50}=73.20 \mu \mathrm{g} / \mathrm{mL}\right.$ ) [40]. In DPPH and ABTS assay, ethanol extract (leaves) showed antioxidant activity $\left(\mathrm{SC}_{50}=17.25 \mu \mathrm{g} / \mathrm{mL}\right.$ and $16.47 \mu \mathrm{g} / \mathrm{mL}$, respectively). Antioxidant activity is due to the presence of high levels of polyphenolic compounds [38]. In a study performed with different extracts of $L$. spinosa aerial parts, the highest free radical scavenging activity (DPPH) was stated to the methanol extract $\left(\mathrm{IC}_{50}=0.48 \pm 0.04 \mu \mathrm{g} / \mathrm{mL}\right)$, whereas in the metal chelating activity of ferrous ions $\left(\mathrm{Fe}^{2+}\right)$ assay, the highest activity was observed for hexane extract $\left(\mathrm{IC}_{50}=0.55 \pm 0.08 \mu \mathrm{g} / \mathrm{mL}\right)$ [23] In another study, the antiradical activity $\left(1 / \mathrm{EC}_{50}\right)$ of $L$. spinosa leaf determined by the DPPH method was 0.1 [24]. The same 
TABle 2: Phytochemical profile of Lasia spinosa.

\begin{tabular}{|c|c|c|c|}
\hline Plant parts & Phytochemical class & Compounds & Ref. \\
\hline Leave & Alkaloids & Berberine & [25] \\
\hline \multirow{2}{*}{$\begin{array}{l}\text { Leaf and } \\
\text { root/ } \\
\text { rhizome }\end{array}$} & Aldehyde & p-Hydroxy benzaldehyde & \multirow[b]{2}{*}{ [26] } \\
\hline & Other compounds & $\begin{array}{l}\text { 4-Hydroxybenzoic acid, } 2 \text { - }\left(4^{\prime} \text {-methoxyphenyl)-ethanol, } 4 \text { - }\right. \\
\text { methoxyphenethyl alcohol, 1-tetracosane }\end{array}$ & \\
\hline Stem & Carotenoid & $\begin{array}{c}\alpha \text {-Carotene, } \beta \text {-carotene, } \beta \text {-carotene-5,6, } 5^{\prime}, 6^{\prime} \text {-diepoxide; } 5,6,5^{\prime}, 6^{\prime} \\
\text {-diepoxy-5, } 8,5^{\prime}, 8^{\prime} \text {-tetrahydro- } \beta \text {, cis-neoxanthin }\end{array}$ & $\begin{array}{l}{[24,31]} \\
\text { Priyadarshani and } \\
\text { Jansz, [25] }\end{array}$ \\
\hline \multirow{6}{*}{ Aerial parts } & Terpinoid & Limonene, $\beta$-elemene, squalene, caryophyllene & $\begin{array}{l}\text { [21]; Rahman et al., } \\
{[23]}\end{array}$ \\
\hline & Volatile oil & $\begin{array}{l}\text { Methyl octadec-6,9-dien-12-ynoate, } \alpha \text {-glyceryl-linolenate } \alpha \text {-pinene, } \alpha \text { - } \\
\text { selinene, camphene, } \delta \text {-3-carene, camphor }\end{array}$ & $\begin{array}{l}\text { [21]; Rahman et al., } \\
{[23]}\end{array}$ \\
\hline & Phenolics & 4-Hydroxybenzoic acid, morin, cinnamic acid, syringic acid, gentisic acid & $\begin{array}{l}\text { Rahman et al., }[23] \\
{[21,28]}\end{array}$ \\
\hline & Fatty acids & Methyl ester of oleic acid, palmitic acid, stearic acid, epoxyoleic acid & Rahman et al., [23] \\
\hline & Steroid & Spinasterone, $\beta$-sitosterol, $\gamma$-sitosterol, stigmasterol, campesterol, crinosterol, & $\begin{array}{l}\text { Rahman et al., [23]; } \\
\text { [21] }\end{array}$ \\
\hline & Alkane & Hexatriacontane, heptacosane & Rahman et al., [23] \\
\hline \multirow[t]{2}{*}{$\begin{array}{l}\text { Root/ } \\
\text { rhizome }\end{array}$} & Lignan & $\begin{array}{l}\text { Lyoniresinol, meridinol, secoisolariciresinol; 5,5' -dimethoxysecoiso- } \\
\text { lariciresinol; 2-(4-hydroxy-3,5-dimethoxybenzyl)-3-(4-hydroxy-3- } \\
\left.\text { methoxybenzyl)-1,2-butanediol; ( } 7^{\prime} \mathrm{S}, 8 \mathrm{~S}, 8 \mathrm{R}\right)-4,4^{\prime} \text {-dihydroxy-3,3' } 5,5^{\prime} \\
\text {-tetramethoxy-7' }, 9 \text {-eproxylignan- } 9^{\prime} \text {-ol-7-one; } 5,5^{\prime} \text {-dimethoxy-lariciresinol; } \\
5^{\prime} \text {-methyoxlariciresinol, dihydrodehydrodiconifery alcohol; syringaresinol }\end{array}$ & $\begin{array}{l}\text { Alam et al., [36]; [28, } \\
\text { 29, 32] }\end{array}$ \\
\hline & Phenolic & Procyanidin A1 & {$[30]$} \\
\hline \multirow{3}{*}{ Whole plant } & Phenolic & $\begin{array}{l}\text { Gentisic acid, isovanilic acid, syringic acid, chlorogenic acid, p-hydroxy } \\
\text { benzoic acid, }(+) \text {-catechin }\end{array}$ & {$[28]$} \\
\hline & $\begin{array}{l}\text { Flavonoids } \\
\text { (glycosides and } \\
\text { aglycones) }\end{array}$ & $\begin{array}{l}\text { Vitexin, vitexin } 2 \text { "-O- } \beta \text {-D-glucopyranoside; isorhamnetin } 3 \text {-O-rutinoside, } \\
\text { morin, apigenin, } 3^{\prime} \text {-methyl quercetin-3-O- } \alpha \text {-L-rhamnopyranosyl- }(1 / 6) \beta \text {-D- } \\
\text { glucopyranoside; triglochinin }\end{array}$ & {$[27,28,31]$} \\
\hline & Ketone & Hexahydrofarnesyl acetone & {$[21]$} \\
\hline
\end{tabular}

study reported a total phenolic content of $6.4 \mathrm{mg}$ gallic equivalents/g and total flavonoid content of 4.4 retinol equivalent in L. spinosa leaf [24]. In other studies, L. spinosa showed a total phenolic content of $2.1 \mathrm{mg}$ gallic equivalents/g and low antioxidant activity, through ferric reducing antioxidant power (FRAP) and oxygen radical absorbance capacity (ORAC) assays, in comparison to indigenous vegetables from Southern Thailand, such as young cashew leaves (Anacardium occidentale L.) and Mon-pu (Glochidion zeylanicum (Gaertn.) A.Juss.) [27].

5.2. Anti-Inflammatory. Inflammation is part of the complex biological response of body tissues to harmful stimuli such as pathogens, damaged cells, or irritants [41] and a protective response involving immune system cells, molecular mediators, among others [42-44].

In lipopolysaccharide-induced RAW 264.7 macrophages, the anti-inflammatory activity of L. spinosa leaf extract was addressed [45], is stated that it can activate the nuclear factor- (NF-) kappa B, and nuclear factor erythroid 2-related factor 2/heme-oxygenase-1 (Nrf2/HO-1) pathways and to suppress mitogen-activated protein kinase (MAPK) and phosphoinositide-3-kinase/protein kinase B (PI3K/ Akt) pathways. Furthermore, L. spinosa leaf extract suppresses the upregulation enzyme iNOS (NOS2), COX2, and proinflammatory cytokines (TNF- $\alpha$, IL- $1 \beta$, and IL-6) and increases cytokines (IL-10) which produced antiinflammatory effect [40].

In another study, the anti-inflammatory activity of $L$. spinosa hydroalcoholic extract in xylene-induced ear oedema model mice was assessed, being stated a significant inhibitory effect on oedema formation $17.1 \%$ at $250 \mathrm{mg} / \mathrm{kg}$ and $27.9 \%$ at $500 \mathrm{mg} / \mathrm{kg}$. An inhibitory potential was also stated in a carrageenan-induced paw oedema model rat, and it was highest at $3 \mathrm{~h}$, with $26.72 \%$ inhibition at $250 \mathrm{mg} /$ $\mathrm{kg}$ and $38.70 \%$ at $500 \mathrm{mg} / \mathrm{kg}$, when compared to the standard drugs (diclofenac sodium (10 mg/kg): $29.52 \%$, and phenylbutazone (100 mg/kg): 40.47\%) (Figure 2) [46].

5.3. Antimicrobial. An antimicrobial agent is that able to kill or stop microorganisms' growth. For that, antibacterial and antifungals are used to fight bacterial and fungal infections, respectively [47-49]. Specifically addressing antibacterial, their prolonged use is closely related to a marked decrease 


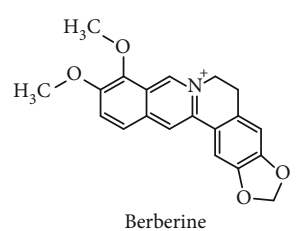<smiles>O=Cc1ccc(O)cc1</smiles><smiles>COc1ccc(CCO)cc1</smiles>

2-(4'-Methoxyphenyl)ethanol<smiles>CC1=CCCC(C)(C)C1/C=C/C(C)=C/C=C/C(C)=C/C=C/C=C(C)/C=C/C=C(C)/C=C\C1=C(C)CCC1(C)C</smiles>

$\alpha$-Carotene<smiles>C=C(C)C1CCC(C)CC1</smiles><smiles>CC(/C=C/C=C(C)/C=C/C(C)=C/C=C/[C@H]1C(C)CCCC1(C)C)=C\C=C\C(C)=C\CC1(C)C(C)CCC1(C)C</smiles><smiles>C=C1CCC(C)=CCC1C1(C)CC1(C)C</smiles>

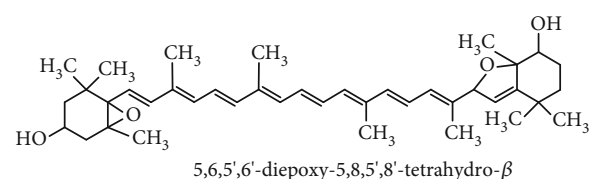

$5,6,5^{\prime}, 6^{\prime}$-diepoxy-5,8,5', $8^{\prime}$-tetrahydro- $\beta$

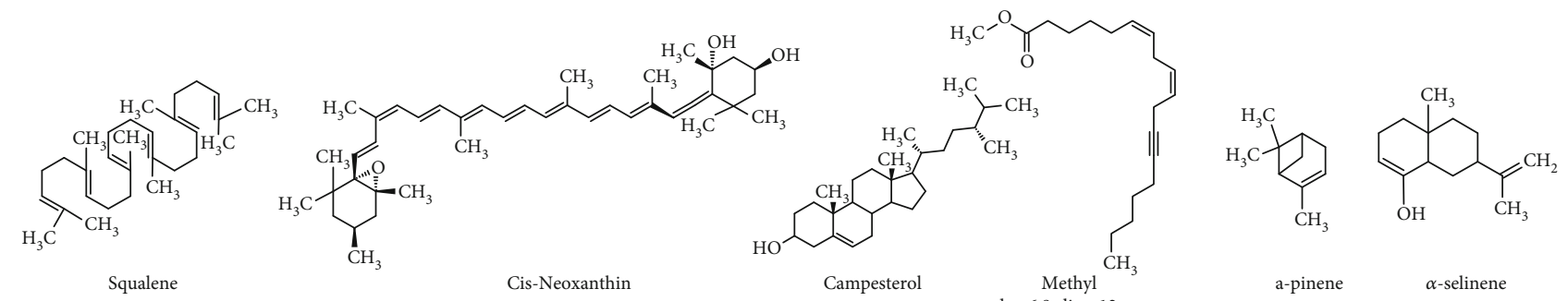<smiles>C=C1C2CCC(C)(C1(C)CC(=O)C(=O)OCC(O)CO)C2(C)C</smiles>

Figure 1: Chemical structures of the most important phytochemicals found in different parts of Lasia spinosa.

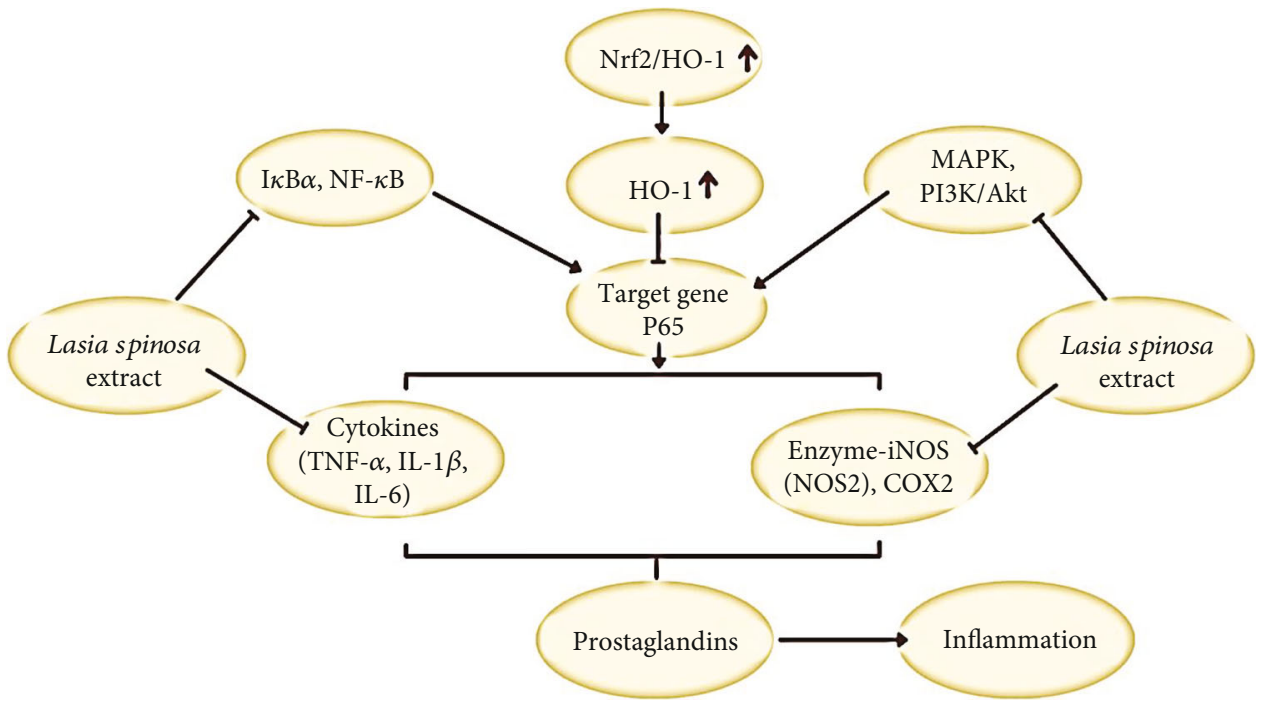

FiguRE 2: Diagram with molecular mechanisms of anti-inflammatory effect of Lasia spinosa.

in the number of enteric bacteria, thus, having a major negative impact on health and wellbeing $[50,51]$. In this sense, the consumption of probiotics and a prebiotics-rich diet may help to replace the destroyed gut microbiota [52]. Stool transplants may also be proposed for patients with difficulty in recovering from prolonged antibiotic treatment, as for recurrent Clostridium difficile infections [53, 54].
The organic extracts (hexane, chloroform, ethyl acetate; $300 \mu \mathrm{g} / \mathrm{disc}$ ) and essential oil of L. spinosa aerial parts showed potent antibacterial activity against Escherichia coli, methicillin-resistant Staphylococcus aureus, Klebsiella pneumoniae, Pseudomonas aeruginosa, and Enterococcus faecalis in comparison of standard antibiotics (tetracycline $30 \mu \mathrm{g} /$ disc, streptomycin $30 \mu \mathrm{g} / \mathrm{disc}$, and erythromycin $15 \mu \mathrm{g} / \mathrm{disc}$ ), 
except for methanol extract [23]. In another study, L. spinosa leaves methanol extract showed moderate antimicrobial properties against Bacillus subtilis, E. coli, Bacillus cereus, $S$. aureus, Candida albicans, Aspergillus niger, and Vibrio para hemolyticus at $400 \mu \mathrm{g} /$ disc by disc diffusion assay [36]. In other studies, the methanol extract of L. spinosa edible parts did not show antimicrobial activity against C. albicans [46].

5.4. Cytotoxic. Cytotoxicity destroys cancer cells or prevents them from multiplying [55-57]. This cytotoxicity is done in different ways: some bioactive compounds can affect the genetic material of cells, and others act by blocking the access of malignant cells to the nutrients needed for division and multiplication [58, 59].

The cytotoxic potential of $L$. spinosa extracts has also been assessed. Brine shrimp lethality bioassay technique was applied to determine the cytotoxic potential of crude extracts. The aqueous extract from $L$. spinosa leaves showed moderate cytotoxicity $\left(\mathrm{LC}_{50}=98.66 \mu \mathrm{g} / \mathrm{mL}\right)$ in brine shrimp lethality bioassay [40], while the methanol extract from the whole plant led to significant cytotoxic effects $\left(\mathrm{IC}_{50}=13.49 \mu \mathrm{g} / \mathrm{mL}\right)$ on brine shrimp [36].

5.5. Antidiarrheal. In the castor oil-induced diarrheal mice model, both standard antimotility drug loperamide and hydroalcoholic extract from L. spinosa root significantly reduced the number of stools in a dose-dependent manner compared to the negative control group. The mean number of stools found was 11.6 for $250 \mathrm{mg} / \mathrm{kg}$ and 8.2 for $500 \mathrm{mg} / \mathrm{kg}$ b.w., whereas for the standard drug $(5 \mathrm{mg} / \mathrm{kg})$ was of 5.6.L. spinosa root extract at $250 \mathrm{mg} / \mathrm{kg}$ b.w, causing a little increase in the latent period, but at $500 \mathrm{mg} / \mathrm{kg}$ b.w. led to a significant increase [46]. L. spinosa root extract exhibited a potent antidiarrheal activity, supporting their traditional use for diarrhea.

5.6. Antihelminthic. Helminthic infections continue to be the major people's health hazard, especially in those living in tropical developing countries [60]. L. spinosa leaves methanol extract significantly exhibited paralysis and triggered worms' death, especially at high doses $(100 \mathrm{mg} / \mathrm{mL})$ against Pheritimaposthuma [61], in a hymenolepisdiminuta-rat animal model [12] and infected mice with Trichinellaspiralis $(800 \mathrm{mg} / \mathrm{kg}$; p.o.) [19].

5.7. Antidiabetic. Diabetes mellitus is a chronic metabolic disease with numerous complications, like retinopathy, neuropathy, and peripheral vascular insufficiency. Several synthetic agents are available for diabetes treatment, but several side effects have been reported [62]. Plant-based medicinal products have been used since ancient times to manage diabetes in traditional medicine in many countries all over the world. L. spinosa stem hydroalcoholic extract have revealed antidiabetic activity at 200 and $400 \mathrm{mg} / \mathrm{kg}$ (p.o.) in dexamethasone $(10 \mathrm{mg} / \mathrm{kg}$ s.c.)-induced diabetic albino rats by preventing serum glucose levels rise triggered by dexamethasone [63] and significantly reducing the triglycerides levels [64]. This extract also ameliorated hyperglycemia, and it likely has greater therapeutic potential as they may also exert beneficial effects on the clinical course of noninsulin-dependent diabetes mellitus (NIDDM), hypertension, and coronary artery disease [63]. A study developed by Shafie et al. [65] showed inhibitory effects of different parts (leaves, stems, and roots) of L. spinosa extracts (aqueous hot/cold, ethanol) against pancreatic lipase, $\alpha$-amylase, and $\alpha$-glucosidase.

5.8. Antihyperlipidemic. L. spinosa leaves have also the potential to prevent hyperlipidemia-induced pancreatitis in rats at concentrations of 400 and $800 \mathrm{mg} / \mathrm{kg}$ (p.o.) while exerting cardioprotective effects by significantly increasing serum high-density lipoprotein-cholesterol (HDL-c) at $100 \mathrm{mg} / \mathrm{kg}$, p.o., and Triton-X 100 at $480 \mathrm{mg} / \mathrm{kg}$, i.p. in an induced hyperlipidemic animal model [3].

5.9. Antinociceptive. Antinociception is the action or process of blocking the detection of a painful or injurious stimulus by sensory neurons, and antinociceptives are agents that block painful stimulus $[66,67]$. The acetic acid-induced writhing test is used for detecting both central and peripheral analgesia, whereas the hot plate is most sensitive to centrally acting analgesics [68]. In acetic acid-induced writhing and hot plate-induced pain in mice the hydroalcoholic extract of L. spinosa roots revealed antinociceptive activity in mice, being stated $37 \%$ and $50 \%$ writhing inhibition at $250 \mathrm{mg} / \mathrm{kg}$ and $500 \mathrm{mg} / \mathrm{kg}$ b.w., respectively, while increased pain threshold [46]. On the other hand, the methanol extract from L. spinosa leaves at $400 \mathrm{mg} / \mathrm{kg}$ led to a significant decrease in the number of writhes and elongated the reaction time in the acetic acid writhing method and radiant heat tail flicking method, respectively [69].

5.10. Gastroprotective. A study revealed that L. spinosa leaves ethanol extract has gastroprotective effects. In albino rats with indomethacin $(5 \mathrm{mg} / \mathrm{kg}$, p.o. $)$ and cold restrain stressinduced ulcers, 3 doses $(100,200$, and $400 \mathrm{mg} / \mathrm{kg}$, p.o.) of L. spinosa extract were tested, with gastroprotective effects being mainly conferred by the extractability to create a defensive layer in stomach, through scavenging free radicals and inhibiting lipid peroxidation [70]. In gastric secretion studies, L. spinosa significantly evidenced a tendency to decrease gastric juice, free acidity, and total acidity [70]. Thus, after isolation of the individual compounds present in the extract, those responsible for the observed effect can be used both to treat ulcers and to reduce their severity.

5.11. Effect on Reproductive Activity. Testosterone plays an important role in Sertoli and Leydig cell proliferation and hyperplasia that can increase the testis size [71]. Testosterone is also involved in spermatogenesis and the growth and development of testis and male accessory reproductive glands [64]. The hydroalcoholic extract of L. spinosa rhizomes was revealed to be able to increase the serum testosterone levels and sperm count in male rats at $40 \mathrm{~g} / \mathrm{kg}$ b.w. These data were confirmed afterward by an increase in testicular weight and sperm count, with the increase in the absolute weight of testis being attributed to the elevation of androgen biosynthesis leading to an increase in serum testosterone levels [64].

The most important pharmacological properties are summarized in Table 3 and Figure 3. 


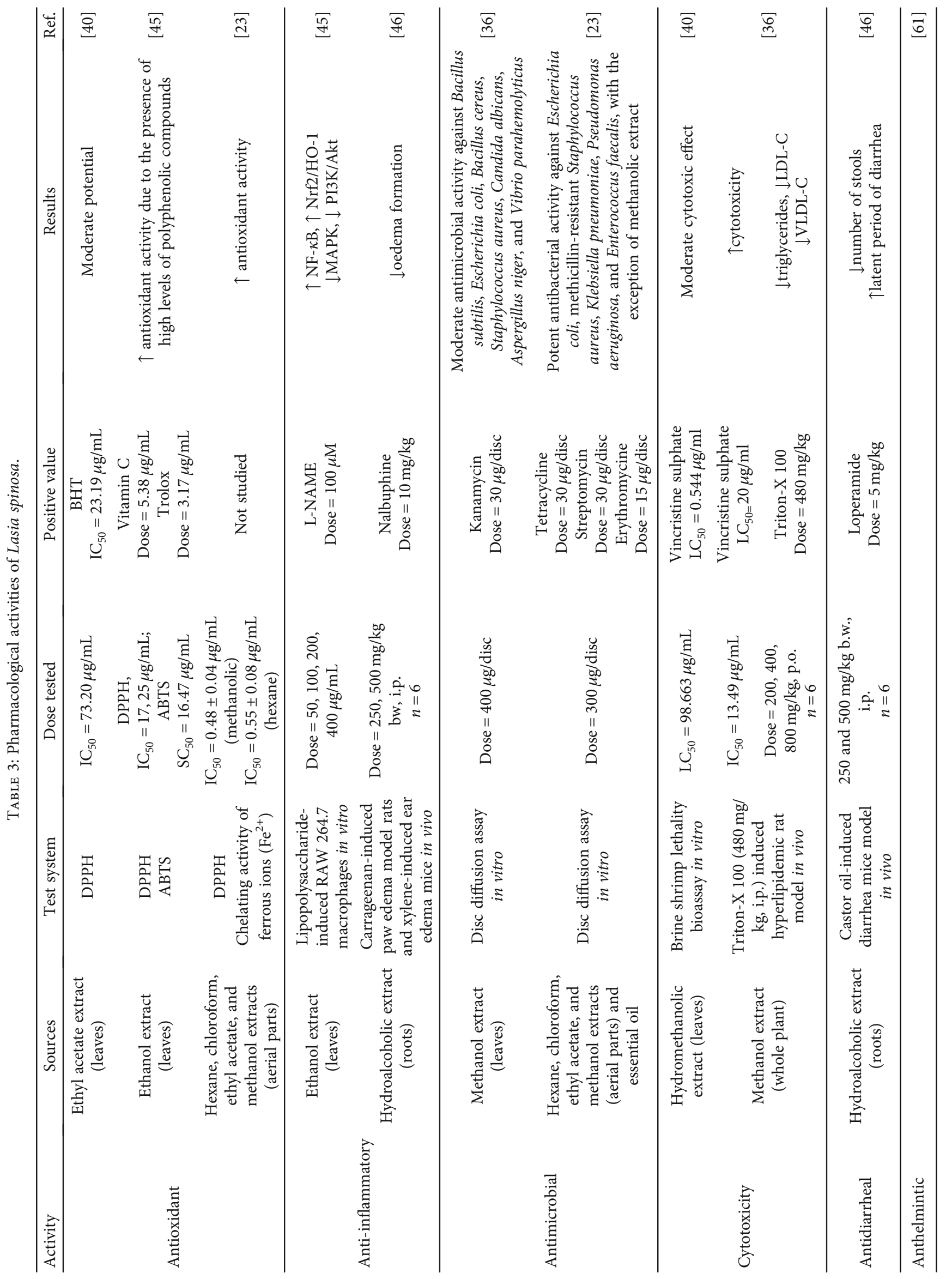




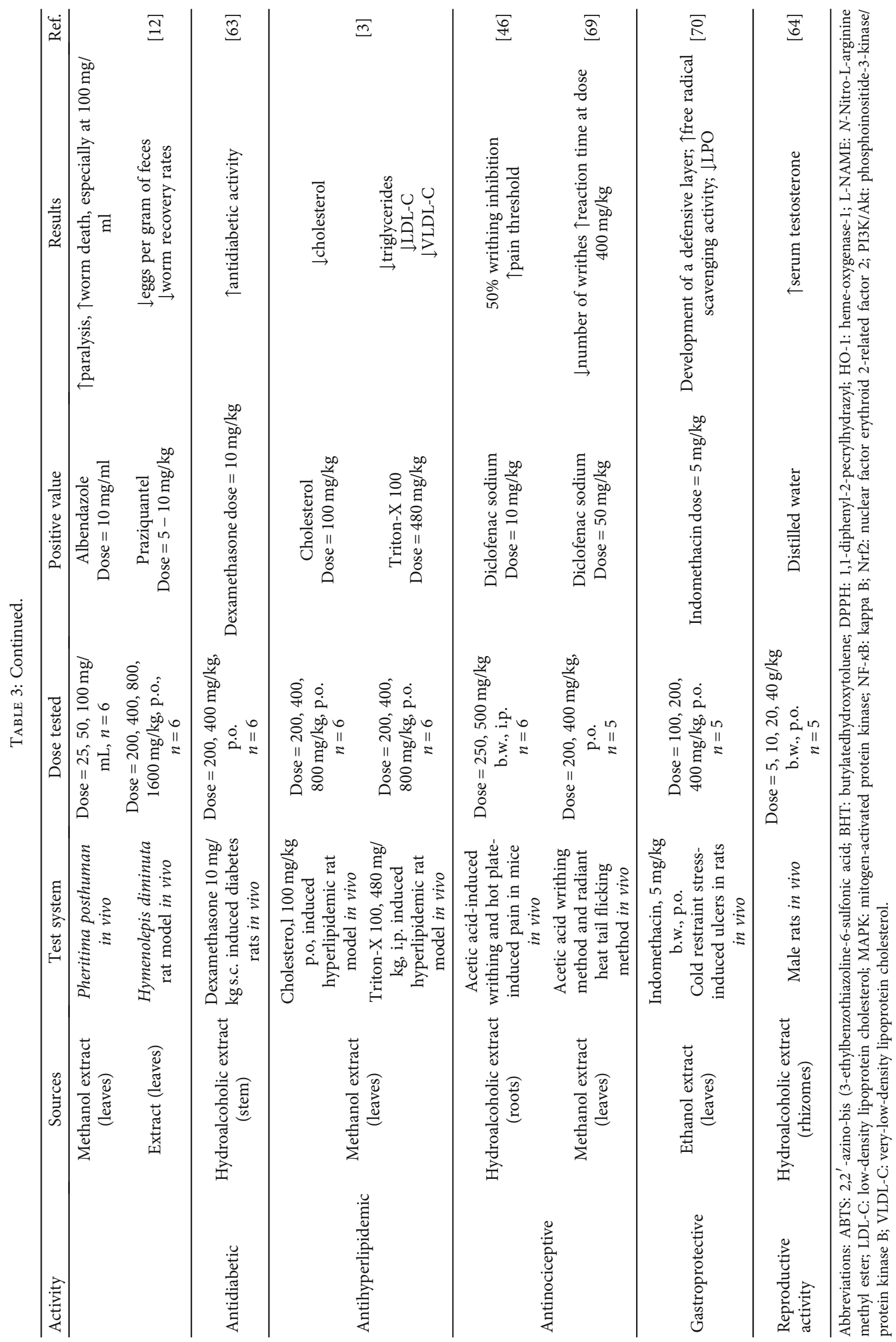




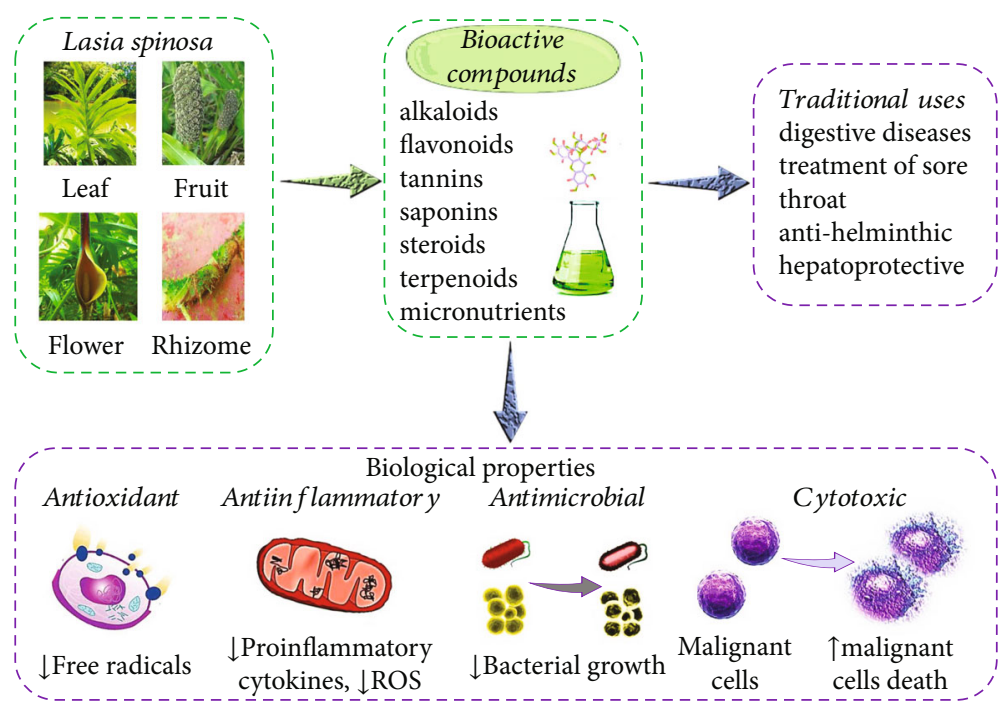

Figure 3: Summarized scheme with traditional uses and the most representative biological properties of L. spinosa.

\section{Toxicological Data and Clinical Gaps}

Oral administration in an acute analysis of 5, 10, 20, and 40 $\mathrm{gm} / \mathrm{kg}$ of an extract, there were no mortality or physiological changes demonstrated. In the subchronic assay for $28 \mathrm{gm} /$ $\mathrm{kg}$, administration of 5 or $20 \mathrm{gm} / \mathrm{kg}$ of extract for $28 \mathrm{gm} /$ $\mathrm{kg}$, no animal deaths were announced that day. No differences in haematological parameters were noticed in either case [52].

Therapeutic limitation of natural bioactive compounds from Lasia spinosa results from the relatively reduced bioavailability of bioactive compounds. In addition, numerous interactions with other prescription drugs may occur. Interactions between medicinal plants interfere with the metabolism or elimination of the drug/chemotherapy from the body. Drug metabolism/elimination is mediated by enzymes that metabolize drugs in the cytochrome P450 (CYP) family and drug transport proteins. These interactions can change the concentration of drugs in the body [72].

Interactions between plants and drugs may occur due to inhibition or activation by plant phytochemicals of CYP enzymes or drug transport proteins that metabolize the drug [73]. Some therapeutic pharmacological agents must be activated by CYP to be effective. Once CYPs are inhibited, such drugs that need to be activated will be ineffective. There may be interactions between plants and drugs that lead to increased elimination of drugs due to CYP activation, which could lead to subtherapeutic exposure to drugs and could lead to therapy failure [74]. Some plant-drug interactions due to CYP inhibition may lead to the accumulation of cytotoxic drugs due to delayed clearance and may increase drug toxicity due to high doses of drugs. Cancer patients are already taking several medications at the same time due to other conditions associated with cancer and comorbidities, which present a risk of drug interactions [75]. The use of herbs/herbal products may further increase the risk of these potentially harmful interactions that interfere with the impact of the drug.

\section{Overall Conclusions and Future Perspectives}

Natural plant sources have contributed to many drug developments. In this study, we comply with the traditional uses, pharmacological properties, and chemical constituents of $L$. spinosa, information that can be useful for further research. Many phytochemicals present in L. spinosa may be responsible for its biological effects in various test systems, but more studies are needed to identify and characterize the active compounds responsible for the pharmacological activities of this hopeful medicinal plant. Future directions must be oriented to toxicological studies which are scarce, and there are necessary new reports to ensure the safety of this plant. Besides, clinical studies are required to confirm the preclinical biological effects in humans.

\section{Conflicts of Interest}

The authors declare that they have no competing interests.

\section{Acknowledgments}

This work was supported by Comisión Nacional de Investigación Científica y Tecnológica (CONICYT) PIA/APOYO CCTE AFB170007. N.C.-M. acknowledges the Portuguese Foundation for Science and Technology under the Horizon 2020 Program (PTDC/PSI-GER/28076/2017).

\section{References}

[1] H. Yuan, Q. Ma, L. Ye, and G. Piao, "The traditional medicine and modern medicine from natural products," Molecules, vol. 21, no. 5, p. 559, 2016.

[2] J. Brahma, S. Chakravarty, and P. Rethy, "Qualitative estimation of the presence of bioactive and nutritional compound in Lasia spinosa: an important vegetable plant used by the Bodos of Kokrajhar District," International Journal of ChemTech Research, vol. 6, pp. 1405-1412, 2014.

[3] S. B. Mahmood, M. Atif, S. R. Ali, M. I. Ahmed, and S. A. Rahman, "Evaluation of antihyperlipidemic activity of methanolic 
leaves extract of Lasia spinosa and its role in prevention of hyperlipidemia induced pancreatitis in rats," International Journal of Pharmaceutical Sciences and Research, vol. 6, no. 4, p. 1502, 2015.

[4] K. Majumdar and B. Datta, "A study on ethnomedicinal usage of plants among the folklore herbalists and Tripuri medical practitioners: part-II," Natural Product Radiance, vol. 6, pp. 66-73, 2007.

[5] A. K. Gupta and L. Spinosa, "IUCN Red List of Threatened Species," in 18th Meeting of the conference of the Parties, Geneva, Switzerland, 2019.

[6] Useful Tropical Plants, 2019, http://tropical.theferns.info/.

[7] R. C. Keating, "Acoraceae and Araceae," in Anatomy of the Monocotyledons, M. Gregory and D. F. Cutler, Eds., pp. 1327, Oxford University Press, Oxford, UK, 2002.

[8] Y. Y. Hiong, "Anti-oxidant activity and total phenolic contents in Cucurbita moschtata, Lasia spinosa and Limnocharis flava, 2005-2009," in School of Food Science and Nutrition, University Malaysia Sabah, 2009.

[9] M. A. Lakshmi, G. V. Priya, and B. G. Rao, "Morpho-anatomical feature and phytochemical assessments of Lasia spinosa (L)Thwaites," Indian Journal of Pharmaceutical Sciences, vol. 82, no. 5, pp. 891-901, 2020.

[10] Flora of China, 1999, http://www.efloras.org/.

[11] Y. N. Shen, D. Xiao, X. X. Hu et al., "First report of leaf spot on Lasia spinosa Caused by Fusarium fujikuroi in China," Plant Disease, vol. 104, no. 9, pp. 2525-2525, 2020.

[12] Y. A. K. Temjenmongla, “Anticestodal efficacy of Lasia spinosa. Extract against experimental Hymenolepis diminuta. Infections in rats," Pharmaceutical Biology, vol. 44, no. 7, pp. 499-502, 2006.

[13] K. N. Reddy, C. Pattanaik, C. S. Reddy, and V. S. Raju, “Traditional knowledge on wild food plants in Andhra Pradesh," Indian Journal of Traditional Knowledge, vol. 6, no. 1, pp. 223-229, 2007.

[14] H. B. Das, K. Majumdar, B. K. Datta, and D. Ray, "Ethnobotanical uses of some plants by Tripuri and Reang tribes of Tripura," Natural Product Radiance, vol. 8, no. 2, pp. 172-180, 2009.

[15] A. Shefana and S. Ekanayake, "Some nutritional aspects of Lasia spinosa (kohila)," Vidyodaya Journal of Science, vol. 14, no. 1, pp. 59-64, 2010.

[16] The Plant List (TPL), 2021, http://www.theplantlist.org/.

[17] M. Heinrich, G. Appendino, T. Efferth et al., "Best practice in research - Overcoming common challenges in phytopharmacological research," Journal of Ethnopharmacology, vol. 246, 2020.

[18] A. K. Gautam, “The wealth of India: an encyclopedia of India's raw material resources," Pakistan Journal of Biological Sciences, vol. 15, no. 5, pp. 449-507, 2001.

[19] A. K. Yadav and Temjenmongla, "Efficacy of Lasia spinosa leaf extract in treating mice infected with Trichinella spiralis," Parasitology Research, vol. 110, no. 1, pp. 493-498, 2012.

[20] T. Temjenmongla and A. K. Yadav, "Anticestodal efficacy of folklore medicinal plants of Naga tribes in north-east India," African Journal of Traditional, Complementary, and Alternative Medicines, vol. 2, no. 2, pp. 129-133, 2005.

[21] L. Deka, R. Majumdar, and A. M. Dutta, "Some ayurvedic important plants from district Kamrup (Assam)," Ancient Science of Life, vol. 3, no. 2, pp. 108-115, 1983.
[22] IAMM, Institute of Aryuveda and Alternative Medicine (IAAM), 2013, http://www.instituteofayurveda.org/.

[23] A. Rahman, S. A. Siddiqui, F. Oke-Altuntas, S. OKAY, F. GÜL, and I. Demirtas, "Phenolic profile, essential oil composition and bioactivity of Lasia spinosa (L.) Thwaites," Brazilian Archives of Biology and Technology, vol. 62, 2019.

[24] P. Maisuthisakul, S. Pasuk, and P. Ritthiruangdej, "Relationship between antioxidant properties and chemical composition of some Thai plants," Journal of Food Composition and Analysis, vol. 21, no. 3, pp. 229-240, 2008.

[25] A. M. B. Priyadarshani and E. R. Jansz, "The effect of maturity on carotenoids of Lasia spinosa stem and the effects of cooking on in-vitro bioaccessibility of carotenoids," Journal of the National Science Foundation of Sri Lanka, vol. 34, no. 3, pp. 131-136, 2006.

[26] M. S. Islam, M. M. Rashid, A. A. Ahmed, A. A. Reza, M. A. Rahman, and T. R. Choudhury, "The food ingredients of different extracts of Lasia spinosa (L.) Thwaites can turn it into a potential medicinal food," NFS Journal, vol. 25, pp. 56-69, 2021.

[27] R. Kongkachuichai, R. Charoensiri, K. Yakoh, A. Kringkasemsee, and P. Insung, "Nutrients value and antioxidant content of indigenous vegetables from southern Thailand," Food Chemistry, vol. 173, pp. 838-846, 2015.

[28] M. Kumar, P. Mondal, S. Borah, and K. Mahato, "Physicochemical evaluation, preliminary phytochemical investigation, fluorescence and TLC analysis of leaves of the plant Lasia spinosa (Lour) Thwaites," International Journal of Pharmacy and Pharmaceutical Sciences, vol. 5, no. 2, pp. 306-310, 2013.

[29] B. Salehi, J. Sharifi-Rad, F. Cappellini et al., "The therapeutic potential of anthocyanins: current approaches based on their molecular mechanism of action," Frontiers in Pharmacology, vol. 11, p. 20, 2020.

[30] R. R. Mititelu, R. Pădureanu, M. Băcănoiu et al., "Inflammatory and oxidative stress markers-mirror tools in rheumatoid arthritis," Biomedicine, vol. 8, no. 5, p. 125, 2020.

[31] B. Salehi, Sharifi-Rad, Capanoglu et al., "Cucurbita plants: from farm to industry," Applied Sciences-Basel, vol. 9, no. 16, p. 3387, 2019.

[32] M. Sharifi-Rad, N. V. Anil Kumar, P. Zucca et al., "Lifestyle, oxidative stress, and antioxidants: back and forth in the pathophysiology of chronic diseases," Frontiers in Physiology, vol. 11, p. 21, 2020.

[33] J. Sharifi-Rad, C. F. Rodrigues, F. Sharopov et al., "Diet, lifestyle and cardiovascular diseases: linking pathophysiology to cardioprotective effects of natural bioactive compounds," International Journal of Environmental Research and Public Health, vol. 17, no. 7, p. 2326, 2020.

[34] M. T. Islam, C. Quispe, M. Martorell et al., "Dietary supplements, vitamins and minerals as potential interventions against viruses: perspectives for COVID-19," International Journal for Vitamin and Nutrition Research, pp. 1-18, 2021.

[35] B. Salehi, A. Rescigno, T. Dettori et al., "Avocado-soybean unsaponifiables: a panoply of potentialities to be exploited," Biomolecules, vol. 10, no. 1, p. 130, 2020.

[36] F. Alam, M. Haque, H. Sohrab, M. A. Monsur, C. M. Hasan, and N. Ahmed, "Antimicrobial and cytotoxic activity from Lasia spinosa and isolated lignan," Latin American Journal of Pharmacy, vol. 30, no. 3, pp. 550-553, 2011.

[37] B. Salehi, A. Prakash Mishra, M. Nigam et al., "Ficus plants: state of the art from a phytochemical, pharmacological, and 
toxicological perspective," Phytotherapy Research, vol. 35, no. 3, pp. 1187-1217, 2021.

[38] B. Salehi, C. Quispe, I. Chamkhi et al., "Pharmacological properties of chalcones: a review of preclinical including molecular mechanisms and clinical evidence," Frontiers in Pharmacology, vol. 11, pp. 592654-592654, 2021.

[39] A. O. Docea, D. Calina, A. M. Buga et al., "The effect of silver nanoparticles on antioxidant/pro-oxidant balance in a murine model," International Journal of Molecular Sciences, vol. 21, no. 4, p. 1233, 2020.

[40] D. Goshwami, M. M. Rahman, M. A. Muhit, M. S. Islam, and M. Anasri, "Antioxidant property, cytotoxicity and antimicrobial activity of Lasia spinosa leaves," Nepal Journal of Science and Technology, vol. 13, no. 2, pp. 215-218, 2013.

[41] C. Scheau, C. Caruntu, I. A. Badarau et al., "Cannabinoids and inflammations of the gut-lung-skin barrier," Journal of Personalized Medicine, vol. 11, no. 6, p. 494, 2021.

[42] R. Padureanu, C. V. Albu, R. R. Mititelu et al., "Oxidative stress and inflammation interdependence in multiple sclerosis," Journal of Clinical Medicine, vol. 8, no. 11, p. 1815, 2019.

[43] G. Georgiadis, I. E. Zisis, A. O. Docea et al., "Current concepts on the reno-protective effects of phosphodiesterase 5 inhibitors in acute kidney injury: systematic search and review," Journal of Clinical Medicine, vol. 9, no. 5, p. 1284, 2020.

[44] D. Calina, A. M. Buga, M. Mitroi et al., "The treatment of cognitive, behavioural and motor impairments from brain injury and neurodegenerative diseases through cannabinoid system modulation-evidence from in vivo studies," Journal of Clinical Medicine, vol. 9, no. 8, p. 2395, 2020.

[45] T. Q. C. Nguyen, T. Duy Binh, T. L. A. Pham et al., "Antiinflammatory effects of Lasia spinosa leaf extract in lipopolysaccharide-induced RAW 264.7 macrophages," International Journal of Molecular Sciences, vol. 21, no. 10, p. 3439, 2020.

[46] D. Deb, S. Dev, A. K. Das et al., "Antinociceptive, antiinflammatory and anti-diarrheal activities of the hydroalcoholic extract of Lasia spinosa Linn. (Araceae) roots," The American Journal of Pharmacy, vol. 29, no. 8, pp. 1269-1276, 2010.

[47] Y. Taheri, N. Joković, J. Vitorović, O. Grundmann, A. Maroyi, and D. Calina, "The burden of the serious and difficult-to-treat infections and a new antibiotic available: cefiderocol," Frontiers in Pharmacology, vol. 11, p. 1922, 2021.

[48] O. Zlatian, A. T. Balasoiu, M. Balasoiu et al., “Antimicrobial resistance in bacterial pathogens among hospitalised patients with severe invasive infections," Experimental and Therapeutic Medicine, vol. 16, no. 6, pp. 4499-4510, 2018.

[49] J. Sharifi-Rad, A. Dey, N. Koirala et al., "Cinnamomum species: bridging phytochemistry knowledge, pharmacological properties and toxicological safety for health benefits," Frontiers in Pharmacology, vol. 12, pp. 600139-600139, 2021.

[50] A. E. Ghenea, R. Cioboată, A. I. Drocaş et al., "Prevalence and antimicrobial resistance of Klebsiella strains isolated from a county hospital in Romania," Antibiotics, vol. 10, no. 7, p. 868, 2021.

[51] J. Sharifi-Rad, C. Quispe, A. Rahavian et al., "Bioactive compounds as potential agents for sexually transmitted diseases management: a review to explore molecular mechanisms of action," Frontiers in Pharmacology, vol. 12, no. 1886, 2021.

[52] J. Sharifi-Rad, C. F. Rodrigues, Z. Stojanović-Radić et al., "Probiotics: versatile bioactive components in promoting human health," Medicina-Lithuania, vol. 56, no. 9, p. 433, 2020.
[53] L. J. Brandt, “American journal of gastroenterology lecture: intestinal microbiota and the role of fecal microbiota transplant (FMT) in treatment of C. difficile infection," The American Journal of Gastroenterology, vol. 108, no. 2, pp. 177-185, 2013.

[54] R. Kellermayer, "Prospects and challenges for intestinal microbiome therapy in pediatric gastrointestinal disorders," World Journal of Gastrointestinal Pathophysiology, vol. 4, no. 4, pp. 91-93, 2013.

[55] A. O. Docea, P. Mitruț, D. Grigore, D. Pirici, D. C. Călina, and E. Gofiță, "Immunohistochemical expression of TGF beta (TGF-beta), TGF beta receptor 1 (TGFBR1), and Ki67 in intestinal variant of gastric adenocarcinomas," Romanian Journal of Morphology and Embryology, vol. 53, no. 3, pp. 683-692, 2012.

[56] O. M. Zlatian, M. V. Comănescu, A. F. Roşu et al., "Histochemical and immunohistochemical evidence of tumor heterogeneity in colorectal cancer," Romanian Journal of Morphology and Embryology, vol. 56, no. 1, pp. 175-181, 2015.

[57] J. Sharifi-Rad, C. Quispe, M. Butnariu et al., "Chitosan nanoparticles as a promising tool in nanomedicine with particular emphasis on oncological treatment," Cancer Cell International, vol. 21, no. 1, pp. 318-318, 2021.

[58] J. Sharifi-Rad, A. Bahukhandi, P. Dhyani et al., “Therapeutic potential of neoechinulins and their derivatives: an overview of the molecular mechanisms behind pharmacological activities," Frontiers in Nutrition, vol. 8, article 664197, 2021.

[59] J. Sharifi-Rad, C. Quispe, J. K. Patra et al., "Paclitaxel: application in modern oncology and nanomedicine-based cancer therapy," Oxidative Medicine and Cellular Longevity, vol. 2021, Article ID 3687700, 2021.

[60] V. Tandon, A. K. Yadav, B. Roy, and B. Das, Phytochemicals as cure of worm infections in traditional medicine systems. Emerging trends in zoology, Narendra Publishing House, New Delhi, 2011.

[61] D. U. Goshwami, M. M. Rahman, M. A. Muhit, and S. Islam, "In-vitro evaluation of anthelmintic activity of Lasia spinosa leaves," International Journal of Current Pharmaceutical Research, vol. 5, no. 1, pp. 34-35, 2013.

[62] A. Pandey, P. Tripathi, R. Pandey, R. Srivatava, and S. Goswami, "Alternative therapies useful in the management of diabetes: a systematic review," Journal of Pharmacy \& Bioallied Sciences, vol. 3, no. 4, pp. 504-512, 2011.

[63] S. Das, M. Baruah, and D. Shill, "Evaluation of antidiabetic activity from the stem of Lasia spinosa in dexamethasone induced diabetic albino rats," Journal of Pharmaceutical, Chemical and Biological Sciences, vol. 1, no. 1, pp. 12-17, 2014.

[64] T. Kaewamatawong, W. Suthikrai, A. Bintvihok, and W. Banlunara, "Acute to subchronic toxicity and reproductive effects of aqueous ethanolic extract of rhizomes of Lasia spinosa Thw. in male rats. Thai," Journal of Veterinary Medicine, vol. 43 , no. 1, p. 74, 2013.

[65] N. H. Shafie, S. L. Idris, N. N. Hamdan et al., "Nutritional composition, antioxidative and inhibitory effects against pancreatic lipase, $\alpha$-amylase and $\alpha$-glucosidase of Lasia spinosa," Journal of Engineering and Applied Science, vol. 13, no. 11, pp. 88988905, 2018.

[66] B. Salehi, S. Sestito, S. Rapposelli et al., "Epibatidine: a promising natural alkaloid in health," Biomolecules, vol. 9, no. 1, p. 6, 2019.

[67] J. Sharifi-Rad, C. Quispe, M. Imran et al., "Genistein: an integrative overview of its mode of action, pharmacological 
properties, and health benefits," Oxidative Medicine and Cellular Longevity, vol. 2021, Article ID 3268136, 2021.

[68] P. Shanmugasundaram and S. Venkataraman, "Anti-nociceptive activity of Hygrophila auriculata (Schum) Heine," African Journal of Traditional, Complementary, and Alternative Medicines, vol. 2, no. 1, pp. 62-69, 2006.

[69] D. Goshwami, M. M. Rahman, M. A. Muhit, and M. S. Islam, "Antinociceptive activity of leaves of Lasia spinosa," Archives of Applied Science Research, vol. 4, no. 6, pp. 2431-2434, 2012.

[70] M. Atif, M. Azharuddin, and S. B. Mahmood, "Gastroprotective potential of Lasia spinosa in albino rats," International Journal of Pharmacy and Pharmaceutical Sciences, vol. 7, no. 3, pp. 254-257, 2015.

[71] D. Calina, A. Docea, K. Golokhvast, S. Sifakis, A. Tsatsakis, and A. Makrigiannakis, "Management of endocrinopathies in pregnancy: a review of current evidence," International Journal of Environmental Research and Public Health, vol. 16, no. 5, p. 781, 2019.

[72] A. Orellana-Paucar and D. Vintimilla-Rojas, "Interactions of clinical relevance associated with concurrent administration of prescription drug and food or medicinal plants: a systematic review protocol," Systematic Reviews, vol. 9, no. 1, p. 1, 2020.

[73] D. Tsoukalas, P. Fragkiadaki, A. Docea et al., "Association of nutraceutical supplements with longer telomere length," International Journal of Molecular Medicine, vol. 44, no. 1, pp. 218226, 2019.

[74] D. Tsoukalas, O. Zlatian, M. Mitroi et al., "A novel nutraceutical formulation can improve motor activity and decrease the stress level in a murine model of middle-age animals," Journal of Clinical Medicine, vol. 10, no. 4, p. 624, 2021.

[75] S. Wanwimolruk and V. Prachayasittikul, "Cytochrome P450 enzyme mediated herbal drug interactions (part 1)," EXCLI Journal, vol. 13, pp. 347-391, 2014. 